\title{
UMA REVISÃo SISTEMÁTICA DA LITERATURA SOBRE PESQUISAS NA INTERFACE CIÊNCIA E ARTE
}

\author{
A SYSTEMATIC REVIEW OF THE LITERATURE ON SOME RESEARCHES IN THE SCIENCE \\ AND ART INTERFACE
}

UNA REVISIÓN SISTEMÁTICA DE LA LITERATURA SOBRE INVESTIGACIONES EN LA INTERFAZ DE CIENCIA Y ARTE

\author{
Raphael Alves Feitosa \\ (iD) 9 \\ Doutorado em Educação (UFC) \\ Professor da Universidade Federal \\ do Ceará (UFC) \\ Docente do Pós-Graduação em \\ Ensino de Ciências e Matemática \\ (PGECM/UFC) e Mestrado \\ Profissional em Ensino de Ciências \\ e Matemática (ENCIMA/UFC) \\ raphael.feitosa@ufc.br
}

\begin{abstract}
Resumo
O objetivo da presente investigação é analisar a literatura de artigos científicos em língua portuguesa contendo a intersecção entre ciência e arte, chamada Sci-Art. Busca-se uma reaproximação, convergência ou até mesmo de intersecção entre arte e ciência, com foco nas contribuições do campo à educação e ao ensino. Procede-se através de uma pesquisa sistemática da literatura no Portal de Periódicos CAPES. Como resultados foram catalogados 26 artigos, abraçando publicações Latino Americanas e Europeias. O levantamento mostra que o campo está em ascensão e vem ganhando espaço nos centros de pesquisa e periódicos.
\end{abstract}

Palavras-chave: Ciência. Arte. Revisão sistemática.

Recebido em: 20 de janeiro de 2021.

Aprovado em: 27 de fevereiro de 2021.

Como citar esse artigo (ABNT):

FEITOSA, Raphael Alves. Uma revisão sistemática da literatura sobre pesquisas na interface ciência e arte. Revista Prática Docente, v. 6, n. 1, e007, 2021. 


\begin{abstract}
The aim of this research is to analyze the literature of scientific articles in Portuguese containing the intersection of science and art, called Sci-Art. We seek a rapprochement, convergence or even intersection between art and science, focusing on the field's contributions to education and teaching. It proceeds through a systematic search of the literature in the Portal of Periodicals CAPES. As a result, 26 articles were cataloged, embracing Latin American and European publications. The survey shows that the field is on the rise and has been gaining space in research centers and journals.
\end{abstract}

Keywords: Science. Art. Systematic review.

\title{
Resumen
}

El objetivo de esta investigación es analizar la literatura de artículos científicos en portugués que contienen la intersección entre ciencia y arte, denominada Sci-Art. Buscamos un acercamiento, convergencia o incluso intersección entre el arte y la ciencia, enfocándonos en las contribuciones del campo a la educación y la docencia. Se procede a través de una búsqueda sistemática de la literatura en el Portal de Publicaciones Periódicas CAPES. Como resultado, se catalogaron 26 artículos, abarcando publicaciones latinoamericanas y europeas. La encuesta muestra que el campo está en aumento y ha ido ganando espacio en los centros de investigación y revistas.

Palabras clave: Ciencia. Arte. Revisión sistemática. 


\section{INTRODUÇÃO: POR ENTRE BIFURCAÇÕES E JUNÇÕES QUE CRIARAM MÚLTIPLOS CAMINHOS}

Muitos autores já refletiram sobre as especificidades, aproximações e as (as)simetrias entre ciência e arte (ATALAY, 2014; FEITOSA, 2020; GARFIELD, 1989; HOCH et al., 2017; ILLINGWORTH; GRIFFITHS, 2019; ROBERTS, 2006). Embora suas atividades possam ser diferentes, cientistas e artistas compartilham alguns componentes essenciais em seu local de trabalho. Ambas as visões de mundo - arte e ciência - procuram interpretar e agir sobre o mundo natural/cultural com base na criatividade e inventividade humana. $\mathrm{O}$ saber e o fazer desses campos constituem duas faces da atividade prática e do conhecimento humano, mediadas por tensões e descompassos.

Do ponto de vista histórico, é recente a segregação entre ciência e arte, ocorrido basicamente nos últimos três séculos, dicotomia imposta sobre nós por meio da especialização do saber-fazer em nossa sociedade e cultura (GARFIELD, 1989). De acordo com Zamboni (2012), do ponto de vista historiográfico, para que a arte pudesse se localizar enquanto área do conhecimento autônoma foi preciso um relativo afastamento aos métodos racionalistas/empiristas foi necessário. Por sua vez, a ciência também se especializou e se ramificou neste período. No entanto, nem sempre foi assim. No Renascimento, por exemplo, essas duas dimensões eram próximas, e as obras de Leonardo da Vinci são um expoente dessa visão (ATALAY, 2014). Os escritos contidos no caderno “Codex Arundel” (1478-1518) de Leonardo da Vinci, conforme analisado por Atalay (2014), são exemplos dessa perspectiva, pois neste material há desde explosões artísticas, até projetos de engenharia, passando pela física, matemática e anatomia humana.

Nessa perspectiva de reaproximação entre ciência e arte, alguns autores sugerem que a aprendizagem bem-sucedida no século XXI exige a conexão horizontal entre as áreas do conhecimento, interligando artes, ciência, tecnologia, engenharia e matemática, demandando novas política e práticas da educação (ILLINGWORTH; GRIFFITHS, 2019). A literatura vem mostrando que essa imbricação ciência-arte, conhecida como Sci-Art (ou SciArt), vem rendendo bons frutos nas áreas de educação e do ensino (FEITOSA, 2020; HOCH et al., 2017; ILLINGWORTH; GRIFFITHS, 2019).

Levando em consideração essa propositura de reaproximação, convergência ou até mesmo de intersecção entre arte e ciência, o objetivo da presente investigação é analisar a literatura que vem sendo publicada na área, em especial de artigos científicos em língua 
portuguesa advindos de periódicos revisados por pares. Desta feita, espero contribuir para uma compreensão sobre os traços recorrentes das investigações, bem como das lacunas que possuem o campo. Com isso, acadêmicos que buscam adentrar na Sci-Art podem ter um mapa inicial do caminho percorrido até então por nossa literatura e para os pesquisadores sêniores de nossas universidades e centros de pesquisa, podem se beneficiar desse levantamento para a realização de futuras pesquisas.

O tema aqui em voga vem sendo alvo de publicações em vários territórios do globo, sendo relevante percorrer um breve resgate historiográfico sobre isso (EISNER, 2004; ILLINGWORTH; GRIFFITHS, 2019; ZAMBONI, 2012). De início, trago ao diálogo um dos nomes associados à intercessão entre os campos da arte-ciência com um viés educativo foi Garfield (1989). No presente século, Eisner (2004) sugeriu que a prática da educação pode aprender muito com as artes, uma vez que elas nos evocam a reformular as concepções do que a educação pode realizar, incluindo aquelas das áreas científicas.

Apesar de serem encontrados vislumbres sobre tal intercessão na Literatura, o impulso formal para a reconexão entre arte-ciência parece ter sido a publicação de um número temático na prestigiada revista "Nature" intitulado "Artists on Science: Scientists" (ABBOTT; RUTHERFORD, 2005). Em adição, Roberts (2006), Eldred (2016) e Hoch et al. (2017) afirmaram que surgiu de uma intercessão entre esses gêneros através da chamada Sci-Art, cujos proponentes e fontes de financiamento procuram promover interações entre os dois campos, a partir dos primeiros anos do século XXI.

No Brasil, o tema também vem sendo discutido por vários pesquisadores (ANDRADE; NASCIMENTO; GERMANO, 2007; FEITOSA, 2020; FONSECA et al., 2019; GUIMARÃES, 2000; KURY, 2001). Nesse grupo brasileiro diversificado em temas Sci-Art, é destaque a relação entre as descrições científicas a partir de obras artísticas, como desenhos, romances, ilustrações e pinturas produzidas por naturalistas nos períodos do Brasil-Colônia e Imperial, os quais foram temas de alguns estudos acadêmicos, como Guimarães (2000) e Kury (2001).

Andrade, Nascimento e Germano (2007) analisaram a obra artística do surrealista espanhol Salvador Dalí e identificaram elementos e traços relacionados à Física Moderna presentes nas mesmas. Em similar perspectiva, Feitosa (2020) analisou a biografia de Vincent van Gogh, como foco na propositura de uma associação/residência de artistas sugerida pelo pintor holandês na cidade de Arles, Sul da França. Elencando argumentos em torno da formação 
humana a partir da ideia vangoghiana, Feitosa (2020) apresentou alguns aspectos da relação entre arte, ciência e formação de professores no programa brasileiro de Residência Pedagógica.

A Sci-Art brasileira ganhou vislumbres vanguardistas na produção de Fonseca et al. (2019). O grupo de cientistas-artistas idealizou uma série de obras usando moscas da fruta (Drosophila melanogaster) transgênicas, as quais foram geneticamente modificadas por uma de suas integrantes em laboratório. Nessa bioarte, as moscas deram origem a ilustrações, textos e até um livro de artistas. Aqui, nesse tipo de experimentação artístico-científica ou científicoartística as paredes que separam entre os campos caem por terra através do terremoto criativo de seus idealizadores. Essas são junções que criaram múltiplos caminhos para cientistasartistas.

Um tipo similar de obra também pode ser visto em outros países, como apresentou Slesingerova (2017), que examinou outras experiências de Sci-Art na República Tcheca, usando a bioarte que usaram tecidos vivos para produzir arte.

Feito esse caminhar inicial por entre bifurcações e junções que criaram múltiplos percursos para a Sci-Art, a seguir, irei destacar uma forma metodológica para adensar a compreensão sobre o que vem sendo produzido nesse campo, como um mapa, analogia que me permitiu desenvolver a presente investigação sistemática.

\section{ASPECTOS METOdOLÓGICOS: UM MAPA PARA A PESQUiSA SISTEMÁtiCA DE LITERATURA}

Seguindo a descrição das relações entre arte e ciência, com vistas a suas intersecções, apresentadas na seção anterior deste artigo, busquei analisar a literatura que vem sendo publicada na área em língua portuguesa. Para atingir esse objetivo, é importante construir um mapa metódico para, então, percorrer os caminhos que levam à colheita das publicações contidas em meio virtual.

Do ponto de vista metodológico, para a construção desse mapa, guiei-me pela bússola da revisão de literatura do tipo sistemática, como descrito por Clarke e Chalmers (2018). Segundo esses autores, a meta mor de uma investigação sistemática é fornecer um resumo meticuloso de todas as pesquisas primárias disponíveis que podem contribuir com um determinado objetivo de investigação. Uma revisão sistemática usa a literatura publicada existente e tenta estabelecer o estado do conhecimento existente e que são frequentemente usados no desenvolvimento da investigação bibliográfica (CLARKE, 2011). Sobre o tipo de tecido contido no presente mapa, recorro a malha trazida por Okoli (2019), no qual aponta que 
o método sistemático é diferente de outros tipos de pesquisa bibliográfica, haja vista explícito e reprodutível, cabendo ao sistemata indicar os procedimentos usados de maneira cristalina.

Agregando-se a isso, optei para a construção do mapa adicionar os traços e as cores de um processo metodológico de coleta e interpretação dos dados utilizados através de uma análise interpretativa, com base nos autores do aporte teórico-metodológico usado na presente investigação (CORDEIRO, 2007; OKOLI, 2019; SAMPAIO; MANCINI, 2007).

Considerando a indicação metodológica da Cornell University Library (2018), a utilizei como guia para adentrar nas searas virtuais do mundo literário acadêmico, e segui tal abordagem metodológica durante a revisão sistemática: (1) Descrevi o objetivo da pesquisa; (2) Defini os critérios de inclusão e exclusão; (3) Realizei a pesquisa de artigos; (4) Selecionei estudos relevantes para inclusão com base em critérios pré-definidos; (5) Extrai dados dos estudos considerados relevantes; (6) Por fim, apresentarei no tópico a seguir os resultados da análise qualitativa das evidências encontradas.

Como base de pesquisa para a revisão sistemática decidi utilizar como porto de partida o "Portal de Periódicos CAPES" (www.periodicos.capes.gov.br), considerado uma das maiores bibliotecas virtuais de publicações científicas, possuindo mais de 36 mil títulos de periódicos disponíveis para consulta, possuindo 130 bases de dados de referências e resumos para levantamento bibliográfico (CENDON; RIBEIRO, 2018). Além disso, o Portal conta com outros tipos de documentos, além de artigos, possuindo livros eletrônicos, capítulos de livros eletrônicos, teses, dissertações e relatórios e outros tipos de publicações não seriadas (ALMEIDA; GUIMARÃES; ALVES, 2010; CORREA et al., 2009; FERREIRA; MARTINEZ; GALINDO, 2011).

Dito isso, após construir o colorido mapa metodológico, a seguir, irei mapear e percorrer as veredas da arte e ciência dispostas na literatura, expondo o delineamento dos passos seguidos na pesquisa, apresentando, assim, os resultados da produção acadêmica encontrada. De início, mostrarei de maneira cristalina os descritores e resultados numéricos encontrados, passando, logo a seguir, a descrever e analisar criticamente a literatura catalogada.

\section{Resultados \& Discussão: MAPEANdo E PERCORRENDO AS VEREDAS DA ARTE E CIÊNCIA}

A investigação sistemática aqui exposta foi realizada no mês de novembro de 2020. Inicialmente, utilizei a ferramenta "Busca por assunto" contida na página inicial do referido portal CAPES. Adicionei como descritores para a busca os seguintes termos: ciência arte. 
Como resultados potenciais, obtive o absoluto numérico de 16.402 materiais. Considerando a inviabilidade de fazer uma busca minuciosa dentre o total encontrado, recorri a elementos de restrição, ação típica de pesquisas do tipo sistemática (CLARK; CHALMERS, 2018; CORNELL UNIVERSITY LIBRARY, 2018). Clarke (2011) indica que quando o pesquisador não congrega um volume exequível para analisar, o mesmo deve usar mecanismos de restrição para tornar os resultados mais alinhados com o objetivo a ser desenvolvido. Assim, a primeira restrição feita foi a seleção de apenas utilizar "Periódicos revisados por pares". Como resultado, obtive a soma integral de 14.564 artigos, soma ainda considerada inviável para análise.

Diante do colossal conjunto de dados disponível, passei a usar o mecanismo de "Busca Avançada". Daqui em diante, todas as ações que serão descritas como exposição da presente investigação sistemática se banham dentro das águas deste recurso. Usei outro mecanismo de restrição e, agora, passei a utilizar o operador booleano AND, pesquisando os descritores: ciência AND arte. Os operadores booleanos relacionam os descritores no processo de elaboração da investigação bibliográfica (OKOLI, 2019). Visando por uma intersecção entre os termos de interesse, utilizei o operador $A N D$ para recuperar artigos de periódicos cujos títulos ou temas contenham os termos da pesquisa. Como resultado numérico, o portal indicou a presença de 14.558 artigos encontrados, o que foi uma diferença numericamente insignificante se comparada à pesquisa anterior ("Busca por assunto").

Mais uma vez, passei a restringir os resultados visando viabilizar um número exequível para uma análise detalhada. Agora, indiquei os mesmos termos descritores (ciência AND arte), porém com a especificação de sua presença "no título" dos artigos a serem selecionados. Empregada tal modificação, os resultados encontrados foram de um total de 510 artigos revisados por pares, cômputo que considerei propenso a uma análise mais minuciosa.

Desta feita, procedi para o passo seguinte de uma pesquisa sistemática de literatura, isto é, busquei pelos artigos considerados relevantes para investigação. São considerados relevantes os materiais bibliográficos efetivamente afins ao objetivo do presente estudo - artigos publicados em língua portuguesa nos periódicos acadêmicos revisados por pares disponíveis no Portal CAPES. Os critérios de inclusão foram: 1) artigo publicado em língua portuguesa; 2) presença dos descritores no título e/ou subtítulo do mesmo; 3) ademais, realizei a leitura do resumo dos artigos, buscando por informações que os vinculassem ao objetivo da presente investigação. Deste modo, selecionei como artigos relativos o conglomerado total de 26 (vinte e seis) publicações, as quais estão sintetizadas no Quadro 1, a seguir. Ressalto que outros 
descritores usados da pesquisa não provieram resultados relevantes, como os termos: SciArt,

Sci-Art, Arte-Ciência, Arte, Ciências, Ensino de ciências.

Quadro 1 - Resultado dos trabalhos relativos encontrados na pesquisa sistemática de literatura no Portal de Periódicos CAPES

\begin{tabular}{|c|c|c|c|}
\hline $\begin{array}{c}\text { Data do } \\
\text { Trabalho }\end{array}$ & Autor(es) & $\begin{array}{l}\text { Título do } \\
\text { Periódico } \\
\end{array}$ & Relação Arte-Ciência abordada \\
\hline 1986 & Albertin & $\begin{array}{c}\text { Revista } \\
\text { Brasileira de } \\
\text { Zoologia } \\
\end{array}$ & $\begin{array}{l}\text { O estudo analisou as contribuições para o campo da zoologia } \\
\text { de uma coleção de desenhos do século XVII, conhecida sob o } \\
\text { nome de "Thealrum Rerum Naturalium Brasiliae". }\end{array}$ \\
\hline 2003 & $\begin{array}{c}\text { Soares \& } \\
\text { Silva }\end{array}$ & Iberoamericana & $\begin{array}{l}\text { A investigação refletiu sobre as representações de corpos no } \\
\text { Brasil do século XX, através de uma abordagem } \\
\text { multicultural, valendo-se da literatura de escritores como } \\
\text { Clarice Lispector e Euclides da Cunha, e de pintores como } \\
\text { Cândido Portinari, Anita Malfatti e Tarsila do Amaral. }\end{array}$ \\
\hline 2004 & Ianni & Tempo Social & $\begin{array}{l}\text { O manuscrito valeu-se de uma análise discursiva sobre textos } \\
\text { científicos e de recursos ficcionais, propondo aproximações } \\
\text { entre ciência e arte por meio de contrastes e semelhanças } \\
\text { reconhecíveis nessas modalidades. }\end{array}$ \\
\hline 2004 & $\begin{array}{l}\text { Oliveira \& } \\
\text { Conduru }\end{array}$ & Manguinhos & $\begin{array}{l}\text { O trabalho analisou uma série de desenhos e ilustrações } \\
\text { científicas do Instituto Oswaldo Cruz, no qual se expôs sua } \\
\text { história e discute-se a representação na produção artística, } \\
\text { incluindo sua contribuição para o campo da ciência da } \\
\text { natureza e da situação de tal tipo de material no campo das } \\
\text { artes. }\end{array}$ \\
\hline 2005 & Lopes & Manguinhos & $\begin{array}{l}\text { A investigação abordou as interações entre teatro, ciência e } \\
\text { tecnologia, a partir de produções teatrais do Ciência em Cena, } \\
\text { espaço integrante do Museu da Vida. }\end{array}$ \\
\hline 2006 & $\begin{array}{l}\text { Massarani, } \\
\text { Moreira \& } \\
\text { Almeida }\end{array}$ & Manguinhos & $\begin{array}{l}\text { No texto, os autores discutiram as aproximações entre o } \\
\text { saber-fazer artístico e o científico, vistos como elementos } \\
\text { constituintes de duas faces da ação e do pensamento } \\
\text { humanos. }\end{array}$ \\
\hline 2006 & Palma & Manguinhos & $\begin{array}{l}\text { Pesquisou sobre a relação entre teatro e divulgação científica } \\
\text { no projeto "Arte e Ciência no Palco", com uso de montagens } \\
\text { teatrais que abordaram temas científicos. }\end{array}$ \\
\hline 2006 & Pachane & $\begin{array}{l}\text { Educação } \\
\text { Temática } \\
\text { Digital }\end{array}$ & $\begin{array}{l}\text { Investigou as categorias verdade e ciência a partir da } \\
\text { abordagem de textos literários de Carlos Drummond, } \\
\text { Machado de Assis e Lia Neiva, promovendo uma } \\
\text { interlocução entre arte e ciência, entre literatura e } \\
\text { metodologia da pesquisa em educação. }\end{array}$ \\
\hline 2006 & $\begin{array}{l}\text { Reis, Guerra } \\
\text { \& Braga }\end{array}$ & Manguinhos & $\begin{array}{l}\text { O trabalho valeu-se de pinturas do surrealismo, } \\
\text { impressionismo e cubismo, como mote para dialogar com as } \\
\text { relações entre ciência e arte, principalmente no campo da } \\
\text { física. }\end{array}$ \\
\hline 2009 & Dias & $\begin{array}{l}\text { A Cor das } \\
\text { Letras }\end{array}$ & $\begin{array}{l}\text { Explorando a obra literária euclidiana"Os sertões", o artigo } \\
\text { buscou analisar a discursividade e semelhanças entre ciência } \\
\text { e arte. }\end{array}$ \\
\hline 2009 & Zylbersztajn & Alexandria & $\begin{array}{l}\text { O manuscrito oriundo de seção intitulada "Literatura, arte e } \\
\text { ciência", fez uma correlação entre a obra musical-poética de } \\
\text { Rita Lee e Tom Zé, articulada com a clássica tese de } \\
\text { doutorado "Física também é cultura". }\end{array}$ \\
\hline 2010 & Ferreira & $\begin{array}{c}\text { Educação e } \\
\text { Pesquisa }\end{array}$ & $\begin{array}{l}\text { Abordou a construção de uma disciplina de um curso de Pós- } \\
\text { Graduação que busca articular Ciência e Arte como estratégia } \\
\text { de motivação para educação em ciência e saúde. }\end{array}$ \\
\hline
\end{tabular}




\begin{tabular}{|c|c|c|c|}
\hline 2012 & $\begin{array}{l}\text { Kampff, } \\
\text { Meyler \& } \\
\text { Porteiro }\end{array}$ & Urdimento & $\begin{array}{l}\text { O trabalho trouxe uma conexão interdisciplinar entre } \\
\text { educação teatral e neurociência, utilizando instrumentos } \\
\text { digitais de imagem para identificar a ação perceptiva-motora. }\end{array}$ \\
\hline 2013 & Soares & $\begin{array}{l}\text { Educação \& } \\
\text { Realidade }\end{array}$ & $\begin{array}{l}\text { Investigou a intersecção entre o devir-filosofia e devir-arte na } \\
\text { ciência da Educação, buscando na filosofia de Deleuze e } \\
\text { Guattari um meio para superar tais fronteiras. }\end{array}$ \\
\hline 2014 & Pataca & Caiana & $\begin{array}{l}\text { Analisou a arte pictográfica das imagens da "Viagem } \\
\text { Filosófica" de Domingos Vandelli (séc. XVIII), discorrendo } \\
\text { sobre as relações entre cartografia, história natural, náutica e } \\
\text { desenho. }\end{array}$ \\
\hline 2015 & $\begin{array}{l}\text { Agostinho } \\
\text { \& Casaleiro }\end{array}$ & Midas & $\begin{array}{l}\text { Divagaram sobre a SciArt feita por artistas e cientistas, } \\
\text { indicando como temas mais frequentes em trabalhos dessa } \\
\text { natureza as ciências naturais, a música e as novas tecnologias. }\end{array}$ \\
\hline 2015 & Corsino & $\begin{array}{l}\text { Educação \& } \\
\text { Realidade }\end{array}$ & $\begin{array}{l}\text { O manuscrito trouxe um ensaio que incorpora conceitos } \\
\text { bakhtinianos sobre o ensino e a didática, num caminho por } \\
\text { entre as searas da filosofia, educação e as artes. }\end{array}$ \\
\hline 2015 & $\begin{array}{c}\text { Noronha \& } \\
\text { Praça }\end{array}$ & Midas & $\begin{array}{l}\text { A pesquisa apontou o modus operandi e os resultados da } \\
\text { interação entre cientistas e artistas partícipes do projeto } \\
\text { "Rede de Residências: Experimentação Arte, Ciência e } \\
\text { Tecnologia", gerador de obras de caráter experimental e } \\
\text { transdisciplinar. }\end{array}$ \\
\hline 2015 & Oliveira & Midas & $\begin{array}{l}\text { O trabalhou pesquisou as obras do tipo bioarte contidas na } \\
\text { exposição "Nature?" (1999-2000) da artista Marta de } \\
\text { Menezes, indicando a necessidade de novas estratégias } \\
\text { museológicas que abram espaço para a colaboração entre } \\
\text { artistas, cientistas e museus. }\end{array}$ \\
\hline 2015 & Valverde & Midas & $\begin{array}{l}\text { A investigação trouxe um relato das experiências entre } 15 \\
\text { cientistas e } 15 \text { artistas integrantes do projeto "neuston", } \\
\text { implicando uma aproximação arte-ciência por meio da } \\
\text { experiência estética. }\end{array}$ \\
\hline 2017 & Mendonça & Gazeta Médica & $\begin{array}{l}\text { Abordou como tema principal a Ilustração Científica dentro } \\
\text { da anatomia humana, indicando que ela serve de ponte entre } \\
\text { arte e ciência. }\end{array}$ \\
\hline 2017 & $\begin{array}{l}\text { Pereira, Ito, } \\
\text { Nakagaki \& } \\
\text { Carvalho }\end{array}$ & RealizAção & $\begin{array}{l}\text { O manuscrito expôs resultados do processo de elaboração de } \\
\text { uma chave pictórica, com ilustração científica, de uma } \\
\text { família de insetos aquáticos, indicando a relevância dessa arte } \\
\text { para a identificação de material biológico. }\end{array}$ \\
\hline 2017 & Silva & $\begin{array}{c}\text { Revista } \\
\text { Eletrônica } \\
\text { Ludus Scientiae }\end{array}$ & $\begin{array}{l}\text { Num relato de experiência envolvendo um sarau literário e o } \\
\text { ensino de química, o texto abordou a relação entre Ciência e } \\
\text { Arte, identificando os elementos lúdicos na experiência } \\
\text { relatada. }\end{array}$ \\
\hline 2018 & $\begin{array}{l}\text { Teixeira, } \\
\text { Alves \& } \\
\text { Muramatsu }\end{array}$ & $\begin{array}{c}\text { Caderno } \\
\text { Brasileiro de } \\
\text { Ensino de Física }\end{array}$ & $\begin{array}{l}\text { O manuscrito trouxe uma análise de um projeto de } \\
\text { divulgação científica itinerante em ambientes educativos } \\
\text { formais e não-formais (parques, praças públicas e escolas), no } \\
\text { qual a ludicidade, estética e arte servem como elemento para } \\
\text { a divulgação das ciências. }\end{array}$ \\
\hline 2020 & $\begin{array}{c}\text { Carvalho \& } \\
\text { Reis }\end{array}$ & $\begin{array}{c}\text { Caderno } \\
\text { Brasileiro de } \\
\text { Ensino de Física }\end{array}$ & $\begin{array}{l}\text { A investigação traçou uma reflexão sobre as pinturas da } \\
\text { surrealista espanhola Remedios Varo como mote de } \\
\text { discussão sobre questões que permeiam a ciência e o ensino } \\
\text { de física. }\end{array}$ \\
\hline 2020 & $\begin{array}{l}\text { Silva, } \\
\text { Mendonça } \\
\text { \& Souza }\end{array}$ & Holos & $\begin{array}{l}\text { O artigo apontou as contribuições para os processos de ensino } \\
\text { e aprendizagem da utilização do filme "Uma Viagem } \\
\text { Extraordinária" para um grupo de Educação de Jovens e } \\
\text { Adultos, durante as aulas de Física, indicando a relevância da } \\
\text { utilização dessa estratégia para populações com baixa } \\
\text { frequência de acesso a bens culturais. }\end{array}$ \\
\hline
\end{tabular}

Fonte: Elaborado pelo Autor em pesquisa sistemática, 2020. 
Conforme pode ser visto a partir dos dados expostos no Quadro 1, existiu uma predominância de publicações nesta temática oriunda da América Latina, sendo a maior parte do material encontrado (20 artigos) publicada em periódicos do Brasil, e apenas sete trabalhos em revistas de outros países, a saber: Pataca (2014) na Argentina; Soares e Silva (2003) na Espanha; Agostinho e Casaleiro (2015), Mendonça (2017), Noronha e Praça (2015), Oliveira (2015) e Valverde (2015) em Portugal. Notadamente, a restrição aplicada nos resultados à língua portuguesa, como era esperado, privilegiou publicações brasileiras, apesar de encontrar algumas advindas da Europa. Contudo, não foi encontrado nenhum outro material vinculado a países de língua portuguesa, asiática, como de Timor-Leste, tampouco de africanos.

Os resultados refletem a baixa quantidade de revistas indexadas advindas desses países, sobretudo daqueles da África de língua oficial portuguesa. Vários autores indicam que existe uma tendência crescente dos pesquisadores buscarem publicar em língua inglesa, devido ao alcance do idioma de origem anglo-saxónica, o que acaba reduzindo o volume de publicações em Português (CENDON; RIBEIRO, 2018; CORRÊA et al., 2009).

Outro ponto relevante que merece ser discutido a partir desse levantamento de literatura é o aspecto cronológico. Os achados indicaram que o tema aqui pesquisado não é uma novidade na academia, haja vista que já nos idos da década de 1980 já se tem uma publicação (ALBERTIN, 1986). Após um hiato de mais de uma década, o assunto retornou com as publicações de Soares e Silva (2003), Ianni (2004), Oliveira e Conduru (2004). Já na primeira década do século XXI, a temática contou com oito artigos disponíveis. É notório o aumento no número de publicações nos últimos dez anos, sendo um total de quinze publicações a partir dos anos 2010. Tal amplitude vai ao encontro do que indicou Feitosa (2020), ao afirmar que esta área de intersecção entre arte-ciência é um campo de pesquisa em ascensão e vem em crescente aumento do seu número de publicações nos últimos anos.

Após percorrer essas trilhas dos resultados encontrados, é relevante analisar o conteúdo intrínseco a essa gama de publicações. Para tanto, os trabalhos relativos foram categorizados a partir da proposição teórica de autores de referência do campo (FEITOSA, 2020; HOCH et al., 2017; ROBERTS, 2006; SLESINGEROVA, 2017), escolhidas a priori, perfazendo em três caminhos-categorias para os artigos encontrados. No primeiro grupo, categorizei os achados que possuem uma conotação predominantemente artística, nos moldes de uma arte que se inspira nas ciências naturais para desenvolver seus processos. Num segundo, agrupei os artigos do campo das ciências da natureza que se inspiram nas artes e/ou utilizam elementos artísticos 
para analisar fenômenos da natureza ou de sua história/historiografia. Por fim, numa terceira via, ajuntei as publicações que, de uma maneira direta ou indireta, incluem aspectos educativos que buscam (re)aproximar arte-ciência, tanto no ensino formal, como no não-formal e informal. A seguir, descrevo os achados advindos dos caminhos trilhados, seguindo o mapa da revisão sistemática de literatura.

Dentre os artigos que trouxeram uma conotação predominantemente artística, nos moldes de uma arte que se inspira nas ciências naturais para desenvolver seus processos, encontram-se três publicações contidas em um dossier temático da revista portuguesa "Midas" (OLIVEIRA, 2015; NORONHA; PRAÇA, 2015; VALVERDE, 2015), além de outros três títulos surgidos em periódicos diversos (DIAS, 2009; KAMPFFR; MEYLER; PORTEIRO, 2012; SOARES; SILVA, 2003).

Soares e Silva (2003) advogaram em torno do tema corpo, trazendo uma convergência entre arte (dança, fotografia, música, literatura e artes plásticas) e ciências (médicas e educação física), refletindo sobre os padrões corporais da sociedade atual.

Dias (2009) analisou a obra “Os Sertões”, de Euclides da Cunha, perfazendo uma análise linguística e filosófica sobre o sertão brasileiro retratado na obra. Com foco no naturalismo, a autora refletiu sobre as verdades científicas e outras concepções naturalistas presentes na narrativa literária, destacando que: “A ciência e a arte, assim dispostas no texto, não se alternam entre si, mas formam um só discurso, particularmente antitético e antinômico" (DIAS, 2009, p. 138).

Permitir um diálogo interdisciplinar entre formação teatral e neurociências foi o tema da publicação de Kampffr, Meyler e Porteiro (2012), na qual os autores buscaram inspiração na ciência para o campo da formação teatral.

O trabalho de Oliveira (2015) refletiu sobre o saber e o fazer artístico da lisboeta Marta de Menezes, com sua exposição "Nature?", que se utilizou de técnicas no âmbito da biotecnologia. A referida exposição artística trouxe representação de uma estufa, borboletário e imagens de borboletas modificadas pela artista (através da técnica de microcauterização). Assim, esse trabalho pode ser associado a bioarte (FONSECA et al., 2019; SLESINGEROVA, 2017).

Outro trabalho nos mesmos moldes do anterior foi o de Valverde (2015), no qual o pesquisador fez apontamentos acerca de uma experiência transdisciplinar envolvendo trinta partícipes, entre cientistas do Instituto de Investigacións Mariñas (Vigo, Galiza, Espanha) e 
artistas. Utilizando a cooperação e diálogo entre artistas e cientistas, foi feita uma aproximação do mundo dos estudiosos do mar (oceanografia e biologia marinha) e dos fenômenos marinhos do ponto de vista da arte, gerando várias obras artísticas em diversos formatos (literatura, fotografia, desenho, escultura, entre outros).

O programa português "Rede de Residências" foi o tema de Noronha e Praça (2015). Eles descreveram o funcionamento e analisaram as implicações do programa, no qual artistas residentes desenvolveram experimentações artísticas utilizando ferramentas e processos específicos dos laboratórios de investigação científica nos quais fizeram residência entre quatro a nove meses (das áreas de biologia, física, engenharia, imunologia e robótica).

Outro conjunto de publicações foca deveras nos aspectos científicos do mundo natural/humano utilizando conexões com aspectos artísticos para referendar uma análise sistemática e racional sobre os fenômenos. A título de exemplo, Albertin (1986) analisou a coleção de desenhos de história natural, da fauna e da flora brasileiras conhecida como "Thealrum Rerum Naturalium Brasiliae", organizados por artistas holandeses que trabalharam no Brasil, no século XVII, sob o patrocínio do então governador João Maurício de Nassau. Usando uma conotação similar, o trabalho de Pataca (2014) utilizou os dados artísticos contidos em desenhos e pinturas que descreviam em detalhes traços de naturalistas (historiadores naturais) europeus que fizeram Expedições Científicas pelo território amazônico Brasil no século XVIII.

O mesmo tema também apareceu no estudo de Oliveira e Conduru (2004) sobre uma série de ilustrações científicas impressas para comporem um trabalho científico do Instituto Oswaldo Cruz, mas que foram julgadas como equivocadas por cientistas. Os autores indicaram que esse material é relevante historicamente e mostra as modificações do conhecimento científico ao longo do tempo.

A relevância do desenho científico também foi tema de Mendonça (2017). O autor apresentou algumas ilustrações como fonte do conhecimento científico médico ao longo da história, em especial as de caráter anatômico. Indo ao encontro dessa percepção, Pereira e colaboradores (2017) expuseram a técnica de ilustração científica insetos aquáticos, enfatizando que os cientistas, regularmente, recorrem ao auxílio de um ilustrador para realização ou auxílio nas ilustrações.

Um terceiro grupo de trabalhos miraram conectar arte e ciência em prol de contribuições para os caminhos do ensino e da aprendizagem nos mais diversos aspectos e níveis educativos. 
Cronologicamente, essa lista inicia com a publicação de Ianni (2004), donde o autor se muniu das armas da filosofia para propor uma quebra entre as barreiras que segregam ciência e arte por meio das narrativas, vislumbrando uma articulação entre as ciências sociais e as artes. O autor adentra nos contrastes e semelhanças reconhecíveis entre os campos e mostra que uma conciliação é produtiva para a formação humana.

Lopes (2005) refletiu sobre as interações entre teatro, ciência e tecnologia, a partir da experiência teatral do "Ciência em Cena", espaço do Museu da Vida Casa de Oswaldo Cruz/Fiocruz (Rio de Janeiro-RJ), no qual a autora relata algumas peças de teatro científico. Essas últimas foram usadas com intuito educativo, visando munir o público leigo de alguns saberes científicos, nas áreas de ciências naturais e humanas, e da vida de seus realizadores. $\mathrm{O}$ teatro científico também foi tema do artigo de Palma (2006), no qual o autor foi entrevistado e teceu considerações sobre o projeto "Arte e Ciência no Palco" de São Paulo-SP.

Massarani, Moreira e Almeida (2006, p. 10) defenderam a seguinte ideia central: "Ciência e arte: ambas nutrem-se do mesmo húmus, a curiosidade humana, a criatividade, o desejo de experimentar”. Proposição similar também é encontrada em Zylbersztajn (2009, p. 122): "Literatura, música, poesia, cinema, ... aportes culturais que podem (e deveriam) ser mais integrados ao ensino das ciências”. Esses autores resgatam aspectos históricos contidos no passado, no qual arte e ciência estavam juntos sem fronteiras, mas que foram segregados com a especialização dos saberes, mas que agora vêm ganhando status de área com redução, até mesmo de desaparecimento, de delineações rígidas.

Ao discutir as relações entre ciência física e arte (desenho, ilustração e pintura), Reis, Guerra e Braga (2006) apresentaram uma abordagem cultural para a ciência. Destacaram que em tal abordagem pode contribuir para incorporar elementos históricos na produção e no ensino de física, bem como nas demais áreas das ciências da natureza.

A arte literária também foi elencada entre os artigos encontrados na presente pesquisa sistemática. Pachane (2006) se inspirou em poesia, conto e romance literário, apontando a literatura como forma de se abordarem temas complexos das ciências, como a noção de verdade e realidade, com estudantes do ensino superior.

O tema das relações entre arte, ciência, filosofia e educação voltou à tona nos artigos de Ferreira (2010) e Soares (2013). O primeiro refletiu sobre semelhanças/contraposições de diferentes referenciais teóricos dos padrões de interação entre a Educação, Arte e Ciências da 
Saúde. O segundo navegou pelos rios das ideias defendidas por Deleuze e Guattari sobre filosofia, ciência e arte, buscando quebrar as fronteiras do pensamento entre os campos.

$\mathrm{Na}$ intersecção arte-ciência, Agostinho e Casaleiro (2015) buscaram dialogar sobre a fusão da ciência e da arte tendo como ponto de partida o norte da colaboração e da criatividade humana, abrindo espaço para a surpresa e o espanto. No mesmo sentido, Corsino (2015) buscou uma conexão dos dois campos (arte-ciência) a partir do referencial da didática e filosofia da linguagem de Mikhail Bakhtin.

Os espaços abertos de ensino não-formal também foram contemplados nos resultados da presente pesquisa sistemática. Teixeira, Alves e Muramatsu (2018) analisaram os resultados de projeto de divulgação científica itinerante com foco na alfabetização científica.

Um artigo deu ênfase a questões educativas de professores em formação inicial no ensino superior (SILVA, 2017). Silva (2017) indicou em seus resultados que a arte - literatura compartilhada através de saraus e recitais de poesias - contribuiu para a formação dos futuros educadores do campo da química.

Silva, Mendonça e Souza (2020) relataram em sua obra uma experiência envolvendo arte cinematográfica e ensino de física, dentro da Educação de Jovens e Adultos (EJA). Os resultados mostraram que a maioria dos alunos partícipes da atividade mencionaram que as reflexões sobre Ciência e Arte provocadas através da exibição de um filme foram significativas.

Por fim, Carvalho e Reis (2020) denotam a vinculação arte-ciência em seu artigo, no qual utilizaram fontes primárias e secundárias, de algumas pinturas da artista surrealista espanhola Remedios Varo, num mote para refletir sobre questões que permeiam a ciência. Os autores analisam o contexto (pessoal, social e político) da artista junto a temas de relevância para as ciências da natureza no século XX, trazendo elementos para se pensar um ensino de ciências munido de elementos culturais, indo ao encontro dos achados de Andrade, Nascimento e Germano (2007).

\section{Algumas CONSIDERAÇÕES SOBRE A JORNADA PERCORRIDA}

A jornada que percorri no presente processo de elaboração desta revisão sistemática de literatura possibilitou uma visão panorâmica das pesquisas em língua portuguesa que trilharam as vias da conexão ciência e arte (Sci-Art). A totalidade das pesquisas aqui sistematizada mostra um movimento de ascensão dessa área de estudo. No entanto, observou-se um número reduzido de publicações que problematizam a existência de limites entre ciência e arte, ou mesmo daquelas que os transcendem numa perspectiva de vanguarda, como no caso da bioarte. Foi 
encontrada uma predominância de artigos que focam as conexões da ciência com a arte e produzem ações-reflexões para a educação e para o ensino de ciências da natureza (Física, Química, Biológicas e Biomédicas).

Outrossim, uma relevante reflexão que o percurso permitiu indicar é que o tema aqui em análise foi abordado em diferentes públicos e espaços. Os grupos que foram de alguma maneira impactados vão desde crianças e jovens frequentadores de museus, parques e escolas, até adultos. Outro destaque foi a presença da Sci-Art no ensino superior, em especial no campo da formação de professores da área de ciências da natureza.

Os dados obtidos ao longo desse caminhar apontaram como norte para a importância de incluir o debate sobre a Sci-Art na educação em seus múltiplos espaços (formal, informal e não formal), sobretudo no que diz respeito à divulgação científica e ensino de ciências. É importante que a universidade e centros de pesquisa, espaços formadores de cientistas e artistas, reconheçam o papel interdisciplinar que a abordagem da intersecção ciência e arte pode oferecer para a formação humana, contribuindo para a indissociabilidade do trinômio ensino, pesquisa e extensão.

Por fim, acredito ser necessário desenvolver investigações futuras que aprofundem as implicações dos resultados da presente investigação, indicando mudanças para o ensino e/ou a educação em ciências ou educação em ciências, trazendo novos dados empíricos sobre de que forma as artes ajudam nos processos de ensino e aprendizagem.

\section{REFERÊNCIAS}

ABBOTT, Alison; RUTHERFORD, Adam. Editorial. Nature, Londres, n. 434, p. 293, 2005. Disponível em: 〈https://doi.org/10.1038/434293a〉. Acesso em: 07 nov. 2020.

AGOSTINHO, Marta; CASALEIRO, Pedro. Ciência e arte, SciArt: museus, laboratórios, cientistas e artistas. MIDAS - Museus e estudos interdisciplinares, Porto, v. 5, 2015. Disponível em: 〈http://journals.openedition.org/midas/829>. Acesso em: 19 jan. 2021.

ALBERTIN, Petronella J. Arte e ciência no Brasil holandês Theatri Rerum Naturalium Brasiliae: um estudo dos desenhos. Revista Brasileira de Zoologia, Curitiba, v. 3, n. 5, p. 249-326, 1986. Disponível em: 〈https://doi.org/10.1590/S0101-81751986000100001〉. Acesso em: 19 jan. 2021.

ALMEIDA, Elenara Chaves Edler de; GUIMARÃES, Jorge Almeida; ALVES, Isabel Teresa Gama. Dez anos do Portal de Periódicos da Capes: histórico, evolução e utilização. Revista Brasileira de Pós-Graduação, Brasília-DF, v. 7, n. 13, p. 218 - 246, 30 nov. 2010. Disponível em: 〈https://doi.org/10.21713/2358-2332.2010.v7.194>. Acesso em: 07 nov. 2020. 
ANDRADE, Rodrigo Ronelli Duarte; NASCIMENTO, Robson de Sousa; GERMANO, Marcelo Gomes. Influências da Física moderna na obra de Salvador Dalí. Caderno Brasileiro de Ensino de Física, Florianópolis, v. 24, n. 3, p. 400-423, 2007. Disponível em: <https://dialnet.unirioja.es/servlet/articulo?codigo=5165676>. Acesso em: 07 nov. 2020.

ATALAY, Bulent. Math and the Mona Lisa: The Art and Science of Leonardo da Vinci. Washington: Smithsonian Books, 2014.

CARVALHO, Taina de Araújo; REIS, José Claudio. Diálogos entre Ciência e Arte: Uma leitura a partir da obra de Remedios Varo para um Ensino sobre as Ciências. Caderno Brasileiro de Ensino de Física, Florianópolis, v. 37, n. 1, p. 173-196, abr. 2020. Disponível em: 〈https://doi.org/10.5007/2175-7941.2020v37n1p173>. Acesso em: 19 jan. 2021.

CENDON, Beatriz Valadares; RIBEIRO, Nádia Ameno. Análise da literatura acadêmica sobre o Portal Periódico Capes. Revista Brasileira de Inovação, João Pessoa, v.18, n. 2, p. 157-178, maio/ago. 2008. Disponível em: <https://periodicos.sbu.unicamp.br/ojs/index.php/rbi/article/view/8648960>. Acesso em: 4 nov. 2020.

CLARKE, Mike; CHALMERS, Iain. Reflections on the history of systematic reviews. BMJ Evidence-Based Medicine, [S.1.], n. 23, p. 121-122, 2018. Disponível em: <https://ebm.bmj.com/content/23/4/121 >. Acesso em: 07 nov. 2020.

CLARKE, Jene. What is a systematic review? Evidence-Based Nursing, Milton Keynes-UK, n. 14, p. 64, 2011. Disponível em: <https://ebn.bmj.com/content/14/3/64>. Acesso em: 07 nov. 2020.

CORDEIRO, Alexander Magno; OLIVEIRA, Glória Maria de; RENTERÍA, Juan Miguel; GUIMARÃES, Carlos Alberto. Revisão sistemática: uma revisão narrativa. Revista do Colégio Brasileiro de Cirurgiões, Rio de Janeiro, v. 34, n. 6, p. 428-431, 2007. Disponível em: <http://dx.doi.org/10.1590/S0100-69912007000600012>. Acesso em: 4 nov. 2020.

CORNELL UNIVERSITY LIBRARY, Ithaca, NYA. Guide to Conducting Systematic

Reviews: Steps in a Systematic Review. Disponível em:

<https://guides.library.cornell.edu/systematic_reviews>. Acesso em: 4 nov. 2020.

CORREA, Cynthia Harumi Watanabe; CRESPO, Isabel Merlo; STUMPF, Ida Regina Chitto; CAREGNATO, Sonia Elisa. Portal de Periódicos da CAPES: um misto de solução financeira e inovação. Revista Brasileira de Inovação, Campinas, v. 7, n. 1, p. 127-145, 2009.

Disponível em: <https://periodicos.ufpb.br/index.php/pbcib/article/view/5319>. Acesso em: 4 nov. 2020.

CORSINO, Patrícia. Entre Ciência, Arte e Vida: a didática como ato responsivo. Educação \& Realidade, Porto Alegre, v. 40, n. 2, p. 399-419, 2015. Disponível em:

<https://doi.org/10.1590/2175-623646089>. Acesso em: 4 nov. 2020.

DIAS, Léa Costa Santana. O consórcio da ciência e da arte enquanto projeto estético norteador d'Os Sertões, de Euclides da Cunha. A Cor das Letras-UEFS, Feira de SantanaBA, n. 10, p. 133-147, 2009. Disponível em: 
$<$ http://periodicos.uefs.br/index.php/acordasletras/article/view/1527>. Acesso em: 4 nov. 2020.

EISNER, Elliot W. What can Education learn from the Arts about the practice of education? International Journal of Education \& the Arts, [S.1.], v. 5, n. 4, p. 1-13, 2004. Disponível em: 〈http://www.ijea.org/v5n4/>. Acesso em: 4 nov. 2020.

ELDRED, Sheila M. Art-science collaborations: Change of perspective. Nature, Londres, $n$. 537, p. 125-126, 2016. Disponível em: <https://doi.org/10.1038/nj7618-125a >. Acesso em: 4 nov. 2020.

FEITOSA, Raphael Alves. New public policy for teacher training in Brazil: Vincent van Gogh as an inspiration for the action of the Pedagogical Residency program? Policy Futures in Education, Londres, v. 19, n. 1, p. 28-43, First Published, 2020. Disponível em: <https://doi.org/10.1177/1478210320940129>. Acesso em: 19 jan. 2021.

FERREIRA, Francisco Romão. Ciência e arte: investigações sobre identidades, diferenças e diálogos. Educação e Pesquisa, São Paulo, v. 36, n. 1, p. 261-280, 2010. Disponível em: <https://doi.org/10.1590/S1517-97022010000100005>. Acesso em: 4 nov. 2020.

FERREIRA, Sueli Mara Soares Pinto; MARTINEZ, Maria Laura.; GALINDO, Marcos. Estudo de usabilidade do Portal de Periódicos da Capes: análise de perfil do usuário discente da UFPE. Revista Brasileira de Pós-Graduação, Brasília-DF, v. 8, n. 15, p. 61 - 107, 2011. Disponível em: 〈https://doi.org/10.21713/2358-2332.2011.v8.211>. Acesso em: 04 nov. 2020.

FONSECA, Fabíola Fonseca; AGRELI, João; SOUSA, Rosemário; CARVALHO, Alexandre. Manual de como fazer sua mosca transgênica: primeiro livro de artista que só contém verdades. Uberlândia: Editora da UFU, 2019.

GARFIELD, Eugene. Art and Science. Part 1, The Art- Science Connection. Current Contents, [S.1.], n. 8, p. 54-61, 1989. Disponível em:

〈http://www.garfield.library.upenn.edu/essays/v12p054y1989.pdf>. Acesso em: 07 nov. 2020.

GUIMARAES, Manoel Luiz Salgado. História e natureza em von Martius: esquadrinhando o Brasil para construir a nação. História, ciência, saúde-Manguinhos, Rio de Janeiro, v. 7, n. 2, p. 391-413, 2000. Disponível em: <http://dx.doi.org/10.1590/S010459702000000300008>. Acesso em: 19 jan. 2021.

HOCH, Michael; ALEXOPOULOS, Angelos; PREECE, Stephen; STORR, Mick; PETRILLI, Achille. Art@CMS SciArt Workshops. PoS ICHEP2016, n. 1184, p. 1-6, 2017. Disponível em: 〈https://inspirehep.net/literature/1597654>. Acesso em: 07 nov. 2020.

IANNI, Octavio. Variações sobre arte e ciência. Tempo Social, São Paulo, v. 16, n. 1, p. 7 23, 2004. Disponível em: 〈http://dx.doi.org/10.1590/S0103-20702004000100001〉. Acesso em: 19 jan. 2021. 
ILLINGWORTH, Sam; GRIFFITHS, Dave. SciArt: Teaching Across the Interface. EOS: Earth and Space Science News, American Geophysical Union, 29 Jan. 2019. Disponível em: <https://doi.org/10.1029/2019EO114633>. Acesso em: 07 nov. 2020.

KAMPFF, Adam R; MEYLER, Sam; PORTEIRO, Tiago. Cartografar a identidade corporal Diálogo entre arte, pedagogia e ciência Ferramentas audiovisuais (primeiro passo).

Urdimento, Florianópolis-SC, v. 02, n. 19, p. 33-40, 2012. Disponível em:

<https://doi.org/10.5965/1414573102192012033>. Acesso em: 07 nov. 2020.

KURY, Lorelai. Viajantes-naturalistas no Brasil oitocentista: experiência, relato e imagem.

História, ciência, saúde-Manguinhos, Rio de Janeiro, v. 8, supl. p. 863-880, 2001.

Disponível em: 〈http://dx.doi.org/10.1590/S0104-59702001000500004〉. Acesso em: 07 nov. 2020.

LOPES, Thelma. Luz, arte, ciência... ação!. História, ciência, saúde-Manguinhos, Rio de Janeiro, v. 12, supl., p. 401-418, 2005. Disponível em: <http://dx.doi.org/10.1590/S010459702005000400021>. Acesso em: 19 jan. 2021.

MASSARANI, Luisa; MOREIRA, Ildeu de Castro; ALMEIDA, Carla. Para que um diálogo entre ciência e arte?. História, ciência, saúde-Manguinhos, Rio de Janeiro, v. 13, supl. p. 710, 2006. Disponível em: 〈http://dx.doi.org/10.1590/S0104-59702006000500001〉. Acesso em: 19 jan. 2021.

MENDONÇA, Fernando Vilhena de. Ilustração Científica: A Arte de Explicar a Ciência e o Conhecimento. Gazeta Médica, [S.1.], v. 3, n. 4, 2017. Disponível em: <https://doi.org/10.29315/gm.v3i4.52>. Acesso em: 19 jan. 2021.

NORONHA, Ana; PRAÇA, Gonçalo. Programa Rede de Residências: Experimentação Arte, Ciência e Tecnologia. MIDAS - Museus e estudos interdisciplinares, Porto, v. 5, 2015. Disponível em: <http://journals.openedition.org/midas/902〉. Acesso em: 19 jan. 2021.

OKOLI, Chitu. Guia para realizar uma revisão sistemática da literatura. eaD em Foco, Rio de Janeiro-RJ, v. 9, n. 1, e748, 2019. Disponível em:

<https://doi.org/10.18264/eadf.v9i1.748>. Acesso em: 07 nov. 2020.

OLIVEIRA, Cristina Barros. A relação entre arte e ciência na bioarte: estudo do caso da obra Nature? (1999-2000) de Marta de Menezes. MIDAS - Museus e estudos interdisciplinares, Porto, v. 5, 2015. Disponível em: 〈http://journals.openedition.org/midas/869>. Acesso em: 19 jan. 2021.

OLIVEIRA, Ricardo Lourenço de; CONDURU, Roberto. Nas frestas entre a ciência e a arte: uma série de ilustrações de barbeiros do Instituto Oswaldo Cruz. História, ciência, saúdeManguinhos, Rio de Janeiro, v. 11, n. 2, p. 335-384, 2004. Disponível em: <http://dx.doi.org/10.1590/S0104-59702004000200007>. Acesso em: 19 jan. 2021.

PACHANE, Graziela Giusti. Um diálogo possível entre arte e ciência: a literatura nas aulas de metodologia de pesquisa. ETD - Educação Temática Digital, Campinas, v.8, n.1, p.90-105, dez. 2006. Disponível em: 〈https://doi.org/10.20396/etd.v8i1.1110>. Acesso em: 19 jan. 2021. 
PALMA, Carlos. Arte e ciência no palco. História, ciência, saúde-Manguinhos, Rio de Janeiro, v. 13, supl., p. 233-246, 2006. Disponível em: <http://dx.doi.org/10.1590/S010459702006000500014>. Acesso em: 19 jan. 2021.

PATACA, Ermelinda. Arte e ciência na Amazônia no século XVIII: o Prospecto da Vila de Cametá. Caiana - Revista de Historia del Arte y Cultura Visual del Centro Argentino de Investigadores de Arte (CAIA), Ciudad Autónoma de Buenos Aires, n. 5, p. 62-79, 2014. Disponível em:

$\langle$ http://caiana.caia.org.ar/template/caiana.php?pag=articles/article_2.php\&obj=156\&vol=5>. Acesso em: 19 jan. 2021.

PEREIRA, Nathaskia Silva, ITO, Mieko Nagata , NAKAGAKI, Jelly Makoto; CARVALHO, Machado de Carvalho. Ilustração científica: os caminhos entre a Arte e a Ciência.

RealizAção, Dourados, v. 4, n. 7, p. 111-119, 2017. Disponível em: <https://doi.org/10.30612/re-ufgd.v4i7.7255>. Acesso em: 19 jan. 2021.

REIS, José Cláudio; GUERRA, Andreia; BRAGA, Marco. Ciência e arte: relações improváveis?. História, ciência, saúde-Manguinhos, Rio de Janeiro, v. 13, supl., p. 71-87, 2006. Disponível em: 〈http://dx.doi.org/10.1590/S0104-59702006000500005>. Acesso em: 19 jan. 2021.

ROBERTS, Keith. Art and science: Sci-Art: what are the problems?. Biochem (Lond), v. 28, n. 6, p. 7-11, 2006. Disponível em: 〈https://doi.org/10.1042/BIO02806007>. Acesso em: 04 nov. 2020.

SAMPAIO, Rosana F.; MANCINI, M.C. Estudos de revisão sistemática: um guia para síntese criteriosa da evidência científica. Revista Brasileira de fisioterapia, São Carlos, v. 11, n. 1, p. 83-89, 2007. Disponível em: 〈https://doi.org/10.1590/S1413-35552007000100013〉. Acesso em: 04 nov. 2020.

SLESINGEROVA, Eva. BioArt a SciArt. Proplétání věcí, těl a technologií/ BioArt and SciArt: Entanglements of Things, Bodies and Technologies. Sešit pro umění, teorii a příbuzné zóny, [S.1.], v. 2017, p. 40-60, 2017. Disponível em: <http://vvp.avu.cz/wpcontent/uploads/2014/08/Sesit_2017_23_Slesingerova.pdf>. Acesso em: 04 nov. 2020.

SILVA, Camila Silveira da. A ludicidade como princípio formativo para Pibidianos em química no sarau ciência \& arte. Revista Eletrônica Ludus Scientiae (RELuS), Foz do Iguaçu-PR, v. 1, n. 1, p. 114-125, jan./jul. 2017. Disponível em:

<https://doi.org/10.30691/relus.v1i1.779>. Acesso em: 19 jan. 2021.

SILVA, Maria Romênia da; MENDONÇA, Silvia Regina Pereira de; SOUZA, Albérico Teixeira Canário de. Exibição do filme "Uma Viagem Extraordinária" nas aulas de Física: a importância da interligação entre ciência e arte na EJA. HOLOS, [S.1.], v. 1, p. 1-15, fev. 2020. Disponível em: <https://doi.org/10.15628/holos.2020.8238>. Acesso em: 19 jan. 2021.

SOARES, Carmen Lúcia; SILVA, Ana Márcia. Corpos De Um Brasil Multicultural: Diálogos Entre Arte E Ciência. Iberoamericana, Madrid, v. 3, n. 10, p.127-42, 2003. Disponível em: <http://www.jstor.org/stable/41673204>. Acesso em: 19 jan. 2021. 
SOARES, Maria da Conceição Silva. Pesquisas com os cotidianos: devir-filosofia e devir-arte na ciência. Educação e Realidade, Porto Alegre, v. 38, n. 3, p. 731-745, 2013. Disponível em: 〈http://dx.doi.org/10.1590/S2175-62362013000300003>. Acesso em: 19 jan. 2021.

TEIXEIRA, Jonny Nelson Teixeira; ALVES, Luis Augusto; MURAMATSU, Mikiya. Projeto Arte e Ciência no Parque: uma abordagem de divulgação científica interativa em espaços abertos. Caderno Brasileiro de Ensino de Física, Florianópolis-SC, Brasil, v. 27 n. 1, p. 171-187, 2018. Disponível em: 〈https://doi.org/10.5007/2175-7941.2010v27n1p171〉. Acesso em: 19 jan. 2021.

VALVERDE, José Pintado. Neuston. Experimento 1. Explorando a interface. Uma experiência de diálogo entre ciência e arte no âmbito marinho. MIDAS - Museus e estudos interdisciplinares, Porto, v. 5, 2015. Disponível em:

<http://journals.openedition.org/midas/896>. Acesso em: 19 jan. 2021.

ZAMBONI, Silvio. A Pesquisa em Arte: um paralelo entre arte e ciência. 4. ed. Campinas: Autores Associados, 2012.

ZYLBERSZTAJN, Arden. Alexandria - Revista de Educação em Ciência e Tecnologia, Florianópolis-SC, v.2, n.3, p.121-122, nov. 2009. Disponível em:

<https://periodicos.ufsc.br/index.php/alexandria/article/view/38009/29009>. Acesso em: 19 jan. 2021. 